Published in final edited form as:

Vet J. 2011 May ; 188(2): . doi:10.1016/j.tvj1.2010.05.002.

\title{
An outbreak of severe leptospirosis in capuchin (Cebus) monkeys
}

\author{
Barbara Szonyi ${ }^{\mathrm{a},{ }^{*}}$, Piedad Agudelo-Flórez ${ }^{\mathrm{b}}$, Marcela Ramírez ${ }^{\mathrm{b}}$, Natali Moreno ${ }^{\mathrm{b}}$, and Albert I. \\ $\mathrm{Ko}^{\mathrm{C}}$ \\ aDepartment of Population Medicine and Diagnostic Sciences, College of Veterinary Medicine, \\ Cornell University, Ithaca, NY 14853, USA \\ bInstituto Colombiano de Medicina Tropical - Universidad CES, Cra 43 A No 52 Sur-99, \\ Sabaneta, Colombia \\ 'Centro de Pesquisas Gonçalo Moniz, Fundação Oswaldo Cruz, 40296-710 Salvador, Brazil
}

\begin{abstract}
Naturally acquired acute leptospirosis in monkeys is uncommon. This study reports an outbreak of severe leptospirosis among 52 capuchin (Cebus) monkeys that had been rescued from homes and housed in a wildlife rehabilitation center in Colombia in 2007. Case confirmation consisted of Leptospira isolation followed by a polymerase chain reaction targeting the LipL32 gene. The attack and mortality rates were $71 \%$ and $27 \%$, respectively. Sixteen cases were confirmed. Necropsy revealed diffuse jaundice and pulmonary hemorrhage. Multi-locus sequence typing identified the agent to be Leptospira interrogans sequence type 17, indicating rats as the source of infection. An environmental survey confirmed rodent infestation as the cause of the outbreak. The extent of Leptospira transmission between humans and monkeys is unknown. Improper husbandry of non-human primates could create new reservoirs and transmission routes for Leptospira threatening conservation efforts and public health.
\end{abstract}

\section{Keywords}

Leptospirosis; Cebus; Capuchin monkey; Outbreak; Rat

\begin{abstract}
Wildlife trade is an extensive and profitable business in Colombia. Some of the trade is domestic with city dwellers keeping wild animals as pets, often illegally. As part of a movement to protect wildlife in Colombia, Environmental Police (Policia Ambiental) confiscates illegally kept wild animals and places them in rehabilitation centers (shelters) prior to their release. During the year 2009 in the Valle de Aburrá region of Colombia alone, nearly 6000 wild animals were confiscated and 4600 rehabilitated and released back into their natural habitat. In addition to the ethical and conservation concerns, there is a significant public health risk associated with illegal wildlife ownership, as wild animals are thought to be the source of over $70 \%$ of all emerging infections (Chomel et al., 2007).
\end{abstract}

(C) 2010 Elsevier Ltd. All rights reserved.

*Corresponding author. Tel.: +1 607253 3572; fax: +1 607253 3083., bs77@ cornell.edu (B. Szonyi).

Conflict of interest statement

None of the authors of this paper has a financial or personal relationship with other people or organizations that could inappropriately influence or bias the content of the paper. 
Leptospirosis is an emerging worldwide zoonosis caused by bacteria of the genus Leptospira. Rodents and other animals are chronic carriers that excrete pathogenic Leptospira in their urine and contaminate the environment. Infection is acquired via direct or indirect contact with the urine of carrier animals. Humans may develop severe forms of the disease such as Weil's disease (associated jaundice, bleeding and acute renal failure) and pulmonary hemorrhage syndrome, for which case fatality is more than $10 \%$ and $50 \%$, respectively (McBride et al., 2005). Although monkeys are susceptible to experimental leptospirosis, naturally acquired, acute leptospirosis in non-human primates is uncommon (Minette, 1966). Here, we describe an outbreak of severe icterohemorrhagic leptospirosis in a group of confiscated capuchin monkeys in a wild-life center in Colombia.

The study population consisted of 52 capuchin monkeys belonging to three species, namely, brown (Cebus apella), white-fronted (C. albifrons) and white-faced (C. capuchinus). The capuchins are medium-sized, omnivorous monkeys that are endemic to Central and South America. The animals had been confiscated from homes by the Environmental Police and placed for rehabilitation at the Centro de Atención y Valoración de Fauna Silvestre, a wildlife rehabilitation center in the Valle de Aburrá region of Colombia. All 52 monkeys were moved into the shelter between December 2006 and June 2007, and there were no new arrivals later in 2007. Upon arrival, every animal was examined and quarantined for 30 days in the center in individual cages. After the quarantine period, the monkeys were housed in communal wire-mesh enclosures outdoors.

Laboratory confirmation of cases consisted of a two-step process. First, peripheral blood samples from all 52 capuchin monkeys present in the shelter during the study period (with and without clinical signs) were cultured in semisolid Fletcher media beginning January 2007. Subsequently, genomic DNA was extracted from Leptospira positive cultures using Quiamp DNA mini kits (Qiagen) and all positive cultures were confirmed by a polymerase chain reaction (PCR) targeting the LipL32 gene to demonstrate the pathogenic status of the isolate (Levett, 2007). To ensure that the amplicons were LipL32 Leptospira sequences, PCR products from the two index case isolates were purified (Microcon Centrifugal Filter Devices) and sequenced in both directions on a 3130 DNA sequencer (Applied Biosystems). Sequences were examined and aligned using MEGA version 4.0 software (Tamura et al., 2007). Thus laboratory confirmation of cases required both a positive Leptospira culture and a positive PCR demonstrating the presence of the LipL32 virulence gene. We elected to apply stringent case confirmation criteria to rule out the possibility of contamination with non-pathogenic Leptospira species that do not carry the LipL32 gene. Conversely, we defined as 'suspected cases' all capuchin monkeys present in the shelter during the epizootic that were not confirmed cases.

To determine the serovar of the infecting agent, multi-locus sequence typing (MLST) of the index case isolates was performed (Thaipadungpanit et al., 2007). Sequences were obtained and examined using the methods described above. The sequence type of the isolates was determined using the publicly available Leptospira MLST database. ${ }^{1}$ An environmental survey of the shelter was also conducted.

The index cases were identified and confirmed in January 2007, when two monkeys became acutely ill with jaundice and died. Demographic, clinical and necropsy findings in all confirmed and suspected cases are summarized in Table 1 . The majority of monkeys suffered from depression and malnutrition. The most common clinical sign among both confirmed and suspected cases was icterus, followed by lymphadenopathy. Of the 52 capuchin monkeys, 37 (71\%) showed clinical signs consistent with leptospirosis and 14

\footnotetext{
${ }^{1}$ See: http://leptospira.mlst.net.
} 
monkeys (27\%) died. There were 16 confirmed cases with a case fatality rate of $44 \%$. Of the confirmed cases, two animals did not exhibit signs of illness consistent with leptospirosis. Necropsy was performed on four confirmed cases and all revealed pulmonary hemorrhage. The monkeys spent an average of 3 months in the rehabilitation center before the onset of clinical signs. No animals were affected while in quarantine in the center (first 30 days). The epizootic lasted from January to August, 2007. The epidemic curve revealed a peak in the number of cases in July (Fig. 1).

Genotyping revealed that the agent for the outbreak was Leptospira interrogans MLST sequence type 17 (serovar Copenhageni/Icterohaemorrhagiae). The DNA sequences have been submitted to GenBank under accession numbers HM049912-HM049925. All monkeys exhibiting signs of illness were isolated and received antibiotic therapy (Streptomycin 20 $\mathrm{mg} / \mathrm{kg}$ for 5 days). Additionally, a quicklime footbath was placed at the entrance of enclosures. Environmental survey indicated signs of active rodent infestation including rat sightings and the presence of droppings in and around the enclosures. Accumulated water and food were also observed on the floor of the enclosures.

This is the first report of a severe leptospirosis outbreak among capuchin monkeys. Naturally acquired fulminant leptospirosis in New World monkeys has been previously reported in a squirrel monkey (Saimiri sciureus) colony in French Guiana (Perolat et al., 1992). Several serological studies in Latin America detected antibodies to Leptospira in various species of apparently healthy non-human primates (Lilenbaum et al., 2005). The agent for the present outbreak, which is carried by the brown rat (Rattus norvegicus), is one of the most common Leptospira serovars affecting humans and animals in urban areas of Latin America (Ko et al., 1999). Recently, a cross sectional study conducted in an urban market near the wildlife shelter has shown that rats were an important reservoir for pathogenic Leptospira organisms in the study area (Agudelo-Florez et al., 2009). Like most New World Monkeys, capuchins are arboreal and have minimal contact with rats in their natural habitat. A captive environment that forces capuchin monkeys to spend time on the ground facilitates their exposure to rodents and increases their risk of Leptospira infection (Minette, 1966).

The monkeys developed clinical signs after relocation from quarantine which suggests that the exposure occurred in the communal enclosure outdoors. The only effective intervention against the agent of this outbreak is rodent control, which would have prevented this epizootic. Short of effective pest control, contact with the urine of carrier rats may have been reduced by securing water bowls on raised stands, providing more branches and elevated platforms for the monkeys to rest on, more frequent cleaning of the floor of the enclosure, and the installation of cement flooring where water cannot accumulate.

The protracted epidemic curve implies continuous exposure of susceptible individuals to Leptospira, as new monkeys arrived to the center occasionally. The sudden increase in the number of cases in July 2007 could be explained by an increase in the number of new arrivals to the shelter earlier that year, which resulted in a higher number of susceptible individuals and crowding in the enclosures. Conversely, the end of the epizootic in August was most likely due to the lack of susceptible individuals, as there were no new arrivals to the center after June in 2007. Although the initial source of infection was the presence of rats, monkey-to-monkey transmission might have contributed to the propagation of the outbreak. The possibility of direct transmission of Leptospira among monkeys has been suggested, but the evidence is circum-stantial (Baulu et al., 1987). It has also been proposed that monkeys may become renal carriers of Leptospira, creating a new reservoir of infection. Although we did not investigate the presence of Leptospira in the urine of infected monkeys, we confirmed two cases with non-specific signs of illness, raising the possibility of 
asymptomatic carriers. The extent of direct Leptospira transmission between humans and non-human primates is unknown. This epizootic emphasizes that inappropriate husbandry practices may create new reservoirs and transmission routes for zoonotic pathogens such as Leptospira, threatening conservation efforts and public health.

\section{Acknowledgments}

This work was supported by the Fogarty International Clinical Research Scholars Program: National Institutes of Health, USA and the Departamento Administrativo de Ciencia, Tecnología e Innovación COLCIENCIAS, Colombia (Cod 325645221265 - 352-2008).

\section{References}

Agudelo-Florez P, Londono AF, Quiroz VH, Angel JC, Moreno N, Loaiza ET, Munoz LF, Rodas JD. Prevalence of Leptospira spp. in urban rodents from a groceries trade center of Medellin, Colombia. American Journal of Tropical Medicine and Hygiene. 2009; 81:906-910. [PubMed: 19861630]

Baulu J, Everard CO, Everard JD. Leptospires in vervet monkeys (Cercopithecus aethiops sabaeus) on Barbados. Journal of Wildlife Diseases. 1987; 23:60-66. [PubMed: 3820429]

Chomel BB, Belotto A, Meslin FX. Wildlife, exotic pets, and emerging zoonoses. Emerging Infectious Diseases. 2007; 13:6-11. [PubMed: 17370509]

Ko AI, Reis MG, Dourado CMR, Johnson WD, Riley LW. Urban epidemic of severe leptospirosis in Brazil. Salvador Leptospirosis Study Group. Lancet. 1999; 354:820-825. [PubMed: 10485724]

Levett PN. Sequence-based typing of Leptospira: epidemiology in the genomic era. PLoS Neglected Tropical Diseases. 2007; 1:e120. [PubMed: 18060079]

Lilenbaum WR, Varges R, Moraes IA, Ferreira AM, Pissinatti A. Leptospiral antibodies in captive lion tamarins (Leontopithecus sp.) in Brazil. Veterinary Journal. 2005; 169:462-464.

McBride AJ, Athanazio DA, Reis MG, Ko AI. Leptospirosis. Current Opinions in Infectious Diseases. 2005; 18:376-386.

Minette HP. Leptospirosis in primates other than man. American Journal of Tropical Medicine and Hygiene. 1966; 15:190-198. [PubMed: 5910526]

Perolat P, Poingt JP, Vie JC, Jouaneau C, Baranton G, Gysin J. Occurrence of severe leptospirosis in a breeding colony of squirrel monkeys. American Journal of Tropical Medicine and Hygiene. 1992; 46:538-545. [PubMed: 1599047]

Tamura K, Dudley J, Nei M, Kumar S. MEGA4: Molecular Evolutionary Genetics Analysis (MEGA) software version 4.0. Molecular Biology and Evolution. 2007; 24:1596-1599. [PubMed: 17488738]

Thaipadungpanit J, Wuthiekanun V, Chierakul W, Smythe LD, Petkanchanapong W, Limpaiboon R, Apiwatanaporn A, Slack AT, Suputtamongkol Y, White NJ, Feil EJ, Day NP, Peacock SJ. A dominant clone of Leptospira interrogans associated with an outbreak of human leptospirosis in Thailand. PLoS Neglected Tropical Diseases. 2007; 1:e56. [PubMed: 17989782]

Vet J. Author manuscript; available in PMC 2013 December 17. 


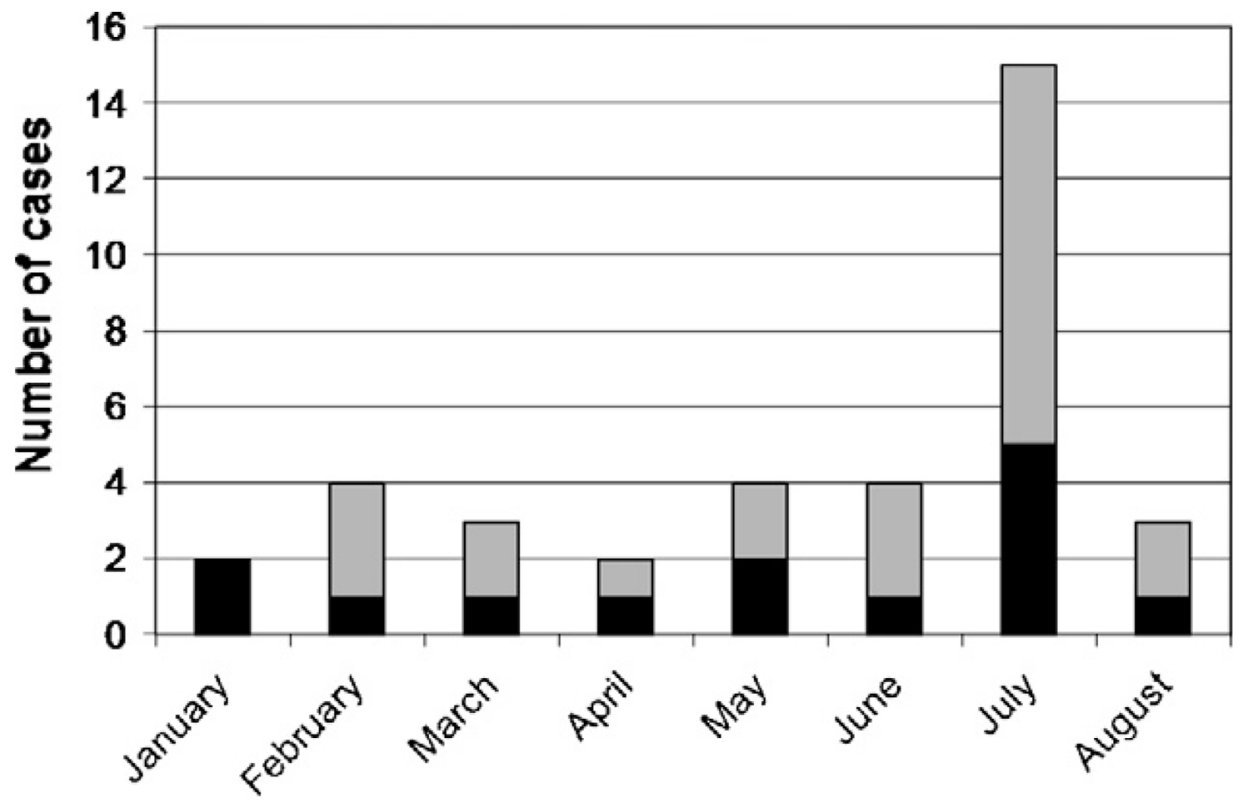

\section{Suspected cases $\square$ Confirmed cases}

Fig. 1.

Epidemic curve based on the onset of symptoms in 37 capuchin monkeys that showed clinical signs consistent with icterohemorrhagic leptospirosis. 


\section{Table 1}

Demographic information, clinical signs, and gross necropsy findings of 52 capuchin monkeys suspected or confirmed of leptospirosis in a wildlife rehabilitation center in Colombia.

\begin{tabular}{|c|c|c|c|c|}
\hline & \multicolumn{2}{|c|}{ Confirmed cases $(n=16)$} & \multicolumn{2}{|c|}{$\underline{\text { Suspected cases }(n=36)}$} \\
\hline & Number & Percent & Number & Percent \\
\hline \multicolumn{5}{|l|}{ Species } \\
\hline C. albifrons & 13 & 81 & 31 & 86 \\
\hline C. capuchinus & 2 & 13 & 4 & 11 \\
\hline C. apella & 1 & 6 & 1 & 3 \\
\hline \multicolumn{5}{|l|}{ Presentation } \\
\hline Lethargy & 10 & 62 & 9 & 25 \\
\hline Emaciation & 8 & 50 & 13 & 36 \\
\hline Dehydration & 3 & 19 & 3 & 8 \\
\hline \multicolumn{5}{|l|}{ Clinical signs } \\
\hline Icterus & 14 & 87 & 23 & 64 \\
\hline Lymphadenomegaly & 9 & 56 & 15 & 42 \\
\hline Pale mucous membranes & 5 & 31 & 10 & 28 \\
\hline Respiratory distress & 5 & 31 & 1 & 3 \\
\hline Abnormal lung sounds & 6 & 37 & 5 & 14 \\
\hline Hepatomegaly & 1 & 6 & 2 & 6 \\
\hline Renomegaly & 2 & 12 & 2 & 6 \\
\hline Melena & 2 & 12 & 2 & 6 \\
\hline No apparent clinical signs & 2 & 12 & 13 & 36 \\
\hline \multicolumn{5}{|l|}{ Outcome } \\
\hline Death & 7 & 44 & 7 & 19 \\
\hline \multicolumn{5}{|l|}{ Necropsy gross findings } \\
\hline Pulmonary hemorrhage & 4 & & & \\
\hline Hemorrhagic mesenteric lymph nodes & 2 & & & \\
\hline Liver congestion & 2 & & & \\
\hline Kidney congestion & 1 & & & \\
\hline
\end{tabular}

Vet J. Author manuscript; available in PMC 2013 December 17. 